
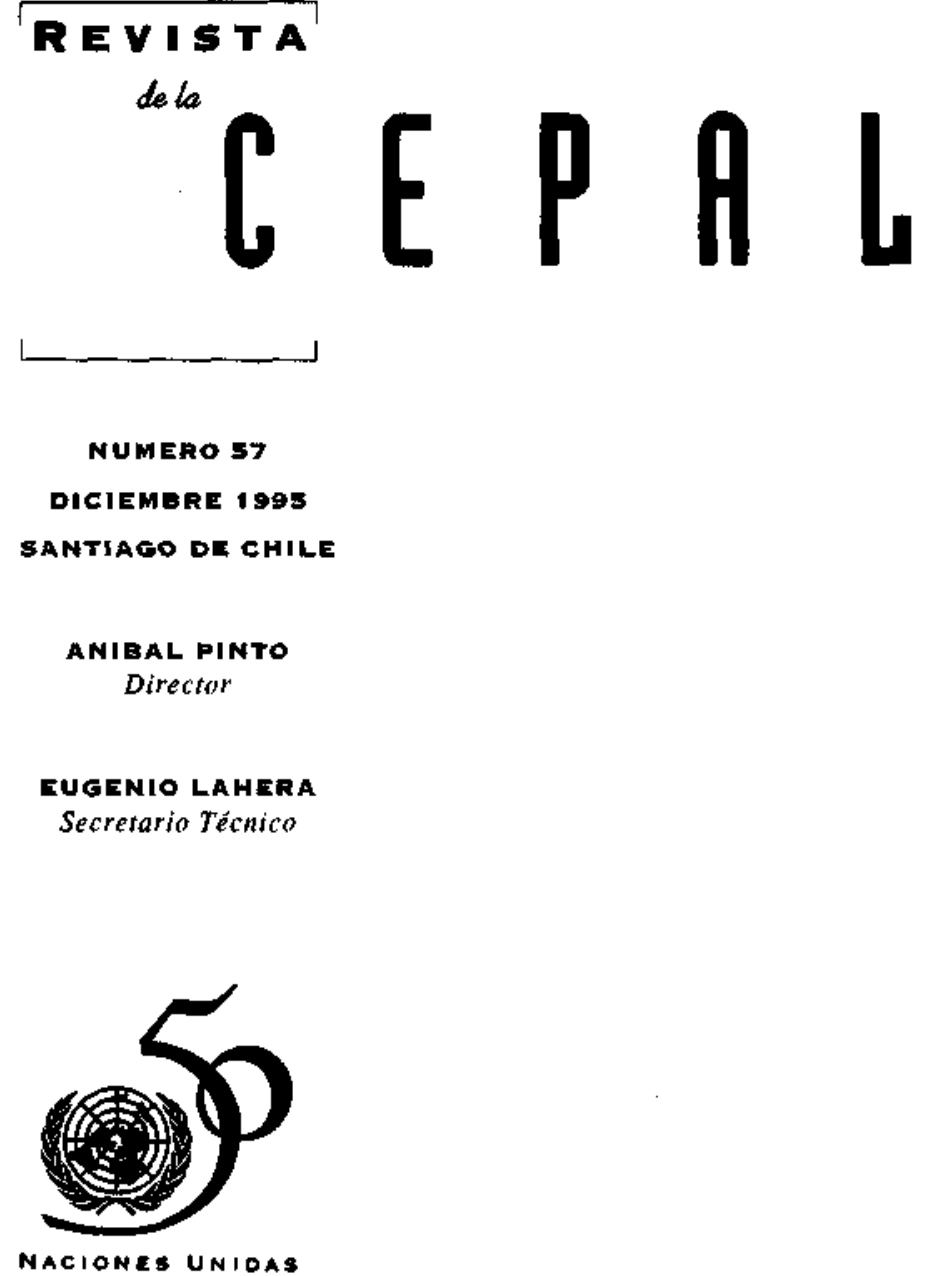
Las Naciones Unidas y la CEPAL en el

Cincuentenario de la Organización

Gert Rosenthal

La creación de las Naciones Unidas y de la CEPAL

Hernán Santa Cruz

Derechos humanos: el caso de los niños

Teresa Albánez

Gobernabilidad, competitividad e integración social

Fernando Calderón

Reforma laboral y equidad social:

la privatización de los puertos

Larry A. Burkhalter

Nuevas tendencias en las políticas salariales

Andrés E. Marinakis

Centroamérica: desempefio macroeconómico y

financiamiento social

Francisco Esquivel

Panamá y la integración económica centroamericana

Luis René Caceres

La dualidad del tipo de cambio en la economía cubana de los noventa

Archibald R.M. Ritter

Transnacionalización e integración productiva en

América Latina

Armando Di Filippo

Indice de autores y de temas en la Revista de la CEPAL, números 1 al 57

Orientaciones para los colaboradores de la Revista de la CEPAL 195 


\section{Centroamérica: desempeño macroeconómico y financiamiento social}

\section{Francisco Esquivel Villegas}

Consultor OPSTOMS

(Costa Rica),

Asesor Económico de

la Secretaría Técnica

de la Comision Regional

de Asuntos Sociales

de Centroamérica.

Profesor e Investigador

de la Escuela de Economía

y de la Maestría en Política

Económica para

Centroamérica, Universidad

Nacional, Heredia, Costa Rica.
El análisis del financiamiento del área social en las economías pequeñas ha adquirido gran importancia en los últimos años, al reconocerse cada vez más la interrelación de los procesos económicos y sociales. La inversión en capital humano se considera fundamental para alcanzar la competitividad que exige la inserción en el comercio mundial. En Centroamérica, la situación sociopolítica ha creado un interés creciente por estudiar el financiamiento del área social, y por conocer el espacio económico que habrá en los próximos años para asignar recursos a la acción social. En este artículo se presenta una propuesta metodológica para el análisis del financiamiento social. Con ella se busca identificar el margen de factibilidad de los programas sociales a partir del entorno macroeconómico, el contex to fiscal y la definición de las políticas internas que establecen la prioridad que cada país asigna a la acción en el área social. Se concluye que para acrecentar el financiamiento social en la subregión serán necesarios avances significativos en estos campos, por lo cual el proceso será largo: no habrá resultados apreciables en el corto plazo, porque la modificación de los factores condicionantes exige un prolongado período de maduración. 


\section{I \\ Introducción}

El análisis del financiamiento del área social en las economías pequeñas ha adquirido gran importancia en los últimos años, al conocerse mejor la interrelación de los procesos económicos y los sociales. Ya no se concibe un desarrollo social aislado del proceso de ajuste estructural y de la estabilización de la economía. Por el contrario, se perciben cada vez con mayor claridad las relaciones recíprocas entre estos dos aspectos del desarrollo.

Ejemplo de lo anterior es el planteamiento sobre desarrollo humano del Programa de las Naciones Unidas para el Desarrollo (PNUD). En él se establece que el logro de un desarrollo integral exige una relación estrecha entre la expansión productiva y la generación de oportunidades para que todos los sectores de la población participen en tal crecimiento. Se considera asimismo que el gasto social es un poderoso instrumento para dotar a los sectores sociales rezagados de capacidad propia para tener éxito en un contexto apropiado de crecimiento. La asignación de recursos a lo social, por lo tanto, no debe interpretarse como un mero proceso redistributivo sino, por el contrario, como la base para crear los recursos humanos que sustentarán el desarrollo material de la sociedad (PNUD, 1991).

De manera similar, en los últimos años, organismos financieros internacionales como el Banco Mundial y el Banco Interamericano de Desarrollo (BID) han procurado conceptualizar el proceso de desarrollo, destacando que la inversión en las personas es básica para un desempeño económico exitoso. Al respecto se ha señalado que las ventajas competitivas alcanzadas por las economías del Asia oriental se cimentaron, entre otros aspectos, en que dieron una apropiada prioridad al gasto público en los sectores sociales, particularmente la inversión en educación básica y en la formación técnica de la población. Dichas economías acumularon así un capital humano que les permitió alcanzar niveles de productividad superiores al de otras similares, con lo cual aumentaron rápidamente su producción y a la vez elevaron sus niveles de equidad (Page, 1994; Leipziger y Thomas, 1994). Por lo tanto, se reconoce ahora que el financiamiento del área social contribuye de manera importante al propio crecimiento económico, pues posibilita la inversión en capital humano que es esencial para la expansión productiva de las economías pequeñas en el entorno globalizado del mundo de hoy.

Esto es apreciado actualmente en Centroamérica, por la situación sociopolítica que vive la subregión. El proceso de pacificación y democratización centroamericano ha llevado a reorganizar sociedades que presentaron severos conflictos en momentos anteriores, y la reconstitución de los sistemas políticos ha permitido procesos de diálogo que apuntan más allá de la sola resolución de los problemas de corto plazo. Ha surgido así un interés cada vez mayor por los temas del desarrollo y la integración subregional, en un contexto bastante amplio de ideas y propuestas de mejoramiento económico y social.

Las reuniones de presidentes centroamericanos de los últimos años han puesto de relieve la preocupación por plasmar un modelo de crecimiento económico que se integre armónicamente con el desarrollo social, para darle bases sólidas a las nuevas sociedades que surgen del proceso descrito. Tras la Declaración de Esquipulas y la realización de las reuniones presidenciales posteriores, la agenda centroamericana ha sido dominada por propuestas para lograr un desarrollo económico y social sustentable, en las cuales la integración desempeña un papel importante como vía solidaria para resolver en conjunto los problemas que obstaculicen el avance hacia ese objetivo.

Las instancias políticas que coordinan el área social en cada uno de los países de la subregión han mostrado una preocupación creciente por conocer cuál será en los próximos años el espacio económico para la asignación de recursos a las acciones de carácter social. Esto sugiere que el estudio del financiamiento social es fundamental para orientar la toma de decisiones en el proceso de asignación de recursos de la sociedad. Sin embargo, debe darse al tema su adecuada dimensión. Las posiciones idealistas que instan a financiar programas sociales sin tener en cuenta las restricciones del entorno económico y fiscal suelen estimular la formulación de planes sin sustento material, que a la postre frustran a las instituciones y a la población que se desea beneficiar al comprobarse la falta de recursos para hacer realidad dichos planes. Por otro lado, hay posiciones pesimistas que provocan el inmovilismo; en particular, si la situación ma- 
croeconómica y la fiscal son desfavorables, se valoran como absolutos los factores del entorno y se asume una actitud mecánica que imposibilita la acción en el área social.

Estos riesgos al decidir la asignación de recursos deben evitarse mediante una valoración apropiada de cada uno de los factores que influyen en el proceso de financiamiento del área social. La propuesta meto- dologica para el análisis del financiamiento social que aquí se postula pretende avanzar hacia la identificación del margen de factibilidad de los programas sociales, a partir de las posibilidades reales del entorno macroeconómico y del contexto fiscal y de la definición de las políticas internas de cada país que establecen cuál ha de ser la prioridad asignada a lo social en el conjunto de las acciones de la sociedad.

II

\section{Propuesta metodológica para}

\section{el estudio del financiamiento social}

El financiamiento social forma parte del proceso de asignación de los recursos escasos de la economía a las diversas necesidades de la sociedad. En consecuencia, no puede examinarse aislado de los aspectos que condicionan tal proceso. Teniendo esto presente se puede realizar un análisis más exhaustivo de las posibilidades reales de lograr determinados niveles de financiamiento social en las condiciones particulares de cada economía. Este enfoque permite superar esquemas anteriores que concebían el financiamiento social como la dotación de recursos a las acciones sociales en función de una prioridad absoluta, dada su importancia en el proceso de desarrollo; dichos esquemas no permiten una acción eficaz de financiamiento cuando los recursos sociales deben gestionarse en un marco de restricción macroeconómica que obliga a conocer con rigurosidad qué espacio económico puede ocupar el área social.

En esta sección se presentará una propuesta metodológica para el estudio del financiamiento social como proceso de asignación de recursos a sectores específicos de la acción estatal, en el marco del comportamiento macroeconómico. Esta propuesta toca los siguientes aspectos explicativos del gasto social por habitante:

PIB
por
habitante $\rightarrow \begin{aligned} & \text { Gasto } \\ & \text { público/ } \\ & \text { PlB }\end{aligned} \rightarrow \begin{aligned} & \text { Gasto } \\ & \text { público } \\ & \text { por } \\ & \text { habitante }\end{aligned} \rightarrow \begin{aligned} & \text { Gasto } \\ & \text { social } \\ & \text { gasto } \\ & \text { público }\end{aligned} \rightarrow \begin{aligned} & \text { Gasto } \\ & \text { social } \\ & \text { por } \\ & \text { habitante }\end{aligned}$

En la propuesta, el punto de partida para la asig. nación de recursos es el tamaño de la economía, medido por su producto interno bruto anual, y el tamaño de su población, que en conjunto indican la capaci- dad de la sociedad para satisfacer las necesidades de cada uno de sus integrantes. Por lo tanto, en nuestra propuesta metodológica el proceso de análisis partirá del producto intemo bruto por habitante (PIB/H), a fin de establecer el ingreso medio que puede asignarse a los miembros de la sociedad. Este es un punto crucial en el estudio de las posibilidades de financiamiento social en economías pequeñas, ya que las diferencias estructurales que se observan en este tipo de economías dan pie a disparidades notorias en el PIB por habitante. También es preciso evaluar las posibilidades de incrementar este PIB ante el reto de Ia globalización, a niveles que no siempre están al alcance de tales economías. La combinación de rezago estructural y de dificultad para insertarse con éxito en el comercio internacional puede obstaculizar una expansión productiva que resuelva la limitación del ingreso existente. Vemos así que las desigualdades de capacidad productiva y de población definen bases materiales que afectan el financiamiento social, aun sin considerar los factores más específicos de la asignación de recursos a este sector de la acción estatal.

Una vez definido el tamaño de la economía, debemos estudiar la capacidad de absorción de recursos que tiene su sector público. El crecimiento del PIB por habitante no garantiza por sí solo una mayor asignación de recursos al presupuesto público. Para garantizar un determinado financiamiento de las acciones públicas se necesitan mecanismos estatales de captación de recursos. El primero de ellos es el sistema tributario, que se define por la voluntad política nacional de financiar el sector público mediante diversas formas de tributos. Otro es el cobro que realiza el Estado por algunos productos o servicios, que 
permite captar recursos cuantiosos en los casos en que el sector público ha diversificado significativamente sus actividades. Además, en economías pequeñas son frecuentes diversas formas de transferencia de recursos del sector no gubernamental al Estado, cuyo origen puede ser interno o externo a la economía. Finalmente, se puede recurrir al endeudamiento para ampliar la capacidad de gasto público, obteniendo el crédito de fuentes internas o externas.

La aplicación de estos mecanismos da como resultado un cierto nivel de gasto público total, que define la cantidad de recursos de la que puede disponer el Estado para el ejercicio de sus diversas funciones. Tales mecanismos reflejan un conjunto de decisiones de asignación que descartan usos alternativos para privilegiar las funciones públicas. En este sentido, es posible definir un indicador que resuma el grado en que una sociedad decide dar prioridad a su sector público, asignándole una determinada proporción de su producto anual. Tal indicador es la relación del gasto público total con el PIB (G/PIB). Este porcentaje define el grado de esfuerzo que hace la sociedad para dotar de una base material a su sector público, por cada unidad de producto generado en la economía. Así —en la metodología que se está presentando- si se aplica la relación G/PIB al PIB por habitante se obtiene el gasto público total por habitante $(\mathrm{G} / \mathrm{H})$. Este $\mathrm{G} / \mathrm{H}$ es resultado de la capacidad de crecimiento del PIB por habitante y de las decisiones de asignación de recursos al sector público expresadas en la relación G/PIB.

Pero la asignación de recursos al sector público no garantiza automáticamente el financiamiento social. Para que los sectores que integran el área social puedan captar parte de los recursos gubernamentales, se necesita una decisión explícita de favorecerlos. Es decir, hay que asignar con cierta preferencia a lo social los recursos que obtenga el Estado. La prioridad dada a lo social se puede medir mediante la relación del gasto social con el gasto público total (GS/o). El porcentaje resultante expresa la voluntad interna del sector público de privilegiar las acciones sociales con cierta cantidad de recursos por unidad de gasto total. Esto confirma que no hay razón para suponer una respuesta directa del gasto social a las fluctuaciones del gasto total. Por el contrario, hay situaciones en que la expansión de los recursos públicos coexiste con el deterioro del gasto social, por haberse dado menor prioridad a éste dentro del gasto público. Asimismo, a veces el gasto social se mantiene o hasta se eleva aunque haya caído el gasto público, gracias a un mejoramiento de la relación GS/G.
De esta manera, en la metodología que se está exponiendo, si se aplica la relación GS/G al G/H obtenemos el gasto social por habitante (GS/H). Este indicador es la medición más apropiada, a nivel agregado, del financiamiento social en una economía, ya que describe la cantidad de recursos sociales que es posible asignar, en promedio, a cada habitante. Desde luego, tal indicador puede desagregarse por sectores sociales y por regiones geográficas, $\mathrm{o}$ bien por grupos beneficiarios. Para facilitar la exposición no nos referiremos aquí a ese tipo de desagregación, pero las conclusiones que se obtendrán a nivel agregado son aplicables a niveles más especfficos de la acción estatal.

En consecuencia, el GS/H es producto de varios factores de diferente naturaleza. Por una parte, el crecimiento de la producción y su relación con la dinámica poblacional establece la capacidad global de generar recursos. Por otra, los mecanismos de captación de recursos públicos definen las posibilidades de financiamiento estatal a partir de los recursos globales de la economía; para esto es importante conocer la relación G/PIB, que expresa la capacidad estatal de captar recursos. Finalmente, la prioridad a lo social dentro del sector público, medida por la relación GS/G, permite efectuar determinada asignación de recursos a los sectores sociales.

Por lo tanto, no es posible definir de antemano relaciones mecánicas entre el entorno macroeconómico y el contexto fiscal, y el comportamiento del gasto social por persona. Debe hacerse un diagnóstico riguroso de cada situación particular para conocer la evolución de cada uno de estos factores, y establecer un orden de causalidad correcto en cada caso. En la sección siguiente, una aplicación al caso centroamericano ilustrará estas afirmaciones.

Cabe destacar que nuestra propuesta metodológica elimina el uso disperso de indicadores del comportamiento del gasto social que suele observarse en diversos diagnósticos. Así, por ejemplo, la relación GS/G $y$ el indicador GS/H por lo general se usan en un mismo análisis de manera separada y sin definir la relación que existe entre ambos. De modo similar se usa la relación del gasto social con el PIB; pero, como se ha visto, dicha relación ya está contenida en la secuencia analítica que va del PIB por habitante al gasto social por habitante, pasando por las etapas intermedias mencionadas. En síntesis, esta propuesta metodológica, más que trabajar con una serie de indicadores dispersos, busca integrarlos en un solo proceso de análisis, en donde cada uno contribuye a la determinación del gasto social por habitante. Observar uno de ellos aisladamente limita la profundidad del análisis. 


\section{III}

\section{El financiamiento social en Centroamérica}

La propuesta metodologica expuesta se puede aplicar al estudio del financiamiento social en Centroamérica. Interesará conocer el comportamiento de los aspectos analizados, para comprender mejor las diferencias que se observan en los recursos asignados al área social en cada país de la subregión. La secuencia del análisis considerará los siguientes aspectos:

\begin{tabular}{|c|c|c|}
\hline \multicolumn{3}{|c|}{ Contexto de crecimiento económico } \\
\hline & & \\
\hline & $\rightarrow$ & PLB por habitante \\
\hline \multicolumn{3}{|l|}{ Tamaño de la población } \\
\hline \multicolumn{3}{|l|}{ Contexto fiscal } \\
\hline \multicolumn{3}{|l|}{$\begin{array}{l}\text { Ingresos tributarios/PIB } \\
\text { Otros ingresos/PIB }\end{array}$} \\
\hline \multicolumn{3}{|l|}{ Endeudamiento/PIB } \\
\hline \multicolumn{3}{|l|}{ Gasto social } \\
\hline $\begin{array}{l}\text { Gasto social/gasto total } \\
\text { (prioridad social) }\end{array}$ & $\rightarrow$ & Gasto social por habitante \\
\hline
\end{tabular}

La combinación de estos elementos, en la secuencia indicada, nos permite explicar el comportamiento del gasto social por habitante como producto de factores de diversa índole.

\section{El contexto de crecimlento económico}

El producto interno bruto por habitante de las economías centroamericanas muestra importantes disparidades (cuadro 1). En la economía guatemalteca, la de mayor tamaño absoluto y a la vez de mayor población de Centroamérica, el PIB por habitante se ubica en un nivel medio entre los valores observados. La economía de Nicaragua, con el menor tamaño absoluto pero con una población bastante elevada en relación con el producto generado, exhibe el PIB por habitante más bajo del ámbito centroamericano. Por otra parte, Panamá y Costa Rica, con un tamaño absoluto considerable para la subregión y una población de magnitud menor, exhiben un PIB por habitante mayor que las otras economías, gracias a la combinación de estos dos aspectos.

Vemos así que hay múltiples combinaciones de PIB y de tamaño de población. Podemos hablar de tres grupos en términos del PIB por habitante. Panamá y Costa Rica se hallan en el nivel más alto, superando $\operatorname{los} 2200$

\begin{tabular}{lccc} 
CUADRO I & $\begin{array}{l}\text { Centroamérica: Producto interno bruto } \\
\text { por habitante } \\
\text { (Dolares de 1993) }\end{array}$ & & \\
\hline & $\begin{array}{l}\text { PlB } \\
\text { (millones } \\
\text { de d6lares) }\end{array}$ & $\begin{array}{l}\text { Población } \\
\text { (miles) }\end{array}$ & $\begin{array}{l}\text { PIB por } \\
\text { habitante } \\
\text { (dólares) }\end{array}$ \\
\hline Costa Rica & 7349 & 3269 & 2248 \\
El Salvador & 7614 & 5517 & 1380 \\
Guatemala & 11330 & 10030 & 1130 \\
Honduras & 3375 & 5336 & 633 \\
Nicaragua & 1866 & 4117 & 453 \\
Panamá & 6381 & 2538 & 2514
\end{tabular}

Fuente: CMCA, 1994; BID, 1994. Elaboración propia.

d6lares (de 1993) por habitante; obtienen este resultado porque son los países con menor población pero con un importante PIB absoluto. En una posición intermedia están El Salvador y Guatemala, con un PIB por habitante entre los 1100 y 1400 dólares; en estos valores influye fuertemente el tamaño de su población. Por último, Honduras y Nicaragua tienen el PIB por habitante menor de la subregión, por la combinación de debilidad productiva y de una población más bien grande para las posibilidades del entorno productivo.

En consecuencia, la base material para la captación de recursos públicos difiere en los grupos de países mencionados, lo que influye en sus posibilidades de asignar recursos al área social. Es decir, ante niveles diferentes del PIB por habitante cabe esperar divergencias en el nivel del gasto público y del gasto social. Sin embargo, podría haber contratendencias que modificaran de alguna manera esta afirmación general, dependiendo de las mediaciones que se produzcan en el contexto fiscal y de la prioridad que se asigne al área social.

\section{El contexto fiscal}

El segundo aspecto de nuestro análisis se refiere a la situación de las finanzas públicas. La información so- 
bre el gasto público en relación con el PIB (cuadro 2) muestra diferencias importantes en el nivel relativo del gasto público entre los distintos datos de cada uno de los países de la subregión. Panamá y Costa Rica aparecen con el sector público de mayor peso relativo en la economía, llegando a proporciones cercanas al $50 \%$ de su PIB. En el resto de los países centroamericanos la cifra fluctúa entre el 10 y el $30 \%$ del PIB. El Salvador y Guatemala presentan el gasto público más bajo, en términos relativos: poco más de $15 \%$ en el primero y cercano al $10 \%$ en el segundo. Por lo tanto, los tamaños relativos del sector público son muy desiguales entre estos dos conjuntos de países. Además, si se recuerda que el PIB por habitante de Panamá y Costa Rica duplica al de El Salvador y Guatemala, se observa una diferencia sustancial en el tamaño relativo del sector público. Es decir, la cantidad de recursos públicos por habitante es menor en El Salvador y Guatemala debido a un PIB por habitante menor y a un peso relativo menor del sector público en el PIB.

CUADRO 2

Centroamérica: Gasto público como porcentaje del producto interno bruto, 1989-1993

(Porcentajes)

\begin{tabular}{ll} 
Costa Rica $^{\mathrm{a}}$ & $\mathbf{5 1 . 4 7}$ \\
El Salvador $^{\mathrm{a}}$ & 15.96 \\
Guatemala $^{\mathrm{b}}$ & 10.76 \\
Honduras $^{\mathrm{b}}$ & 23.19 \\
Nicaragua $^{\mathrm{b}}$ & 28.91 \\
Panama $^{\mathrm{a}}$ & $\mathbf{5 0 . 1 8 ^ { \mathrm { c } }}$ \\
\hline
\end{tabular}

Fuente: CMCA, 1994. Elaboración propia.

a Sector público no financiero.

b Gobierno central.

c Estimación para 1989.

En Nicaragua y Honduras el sector público tiene un peso relativo mayor que en El Salvador y Guatemala. Esto permite a los primeros compensar en cierta medida el rezago de su PIB respecto de estos últimos: por su mayor capacidad de captar recursos públicos, el tamaño de su sector público se acerca un poco más al de Guatemala y El Salvador.

Sin embargo, analizando la subregión en su conjunto, se nota el rezago de estos cuatro países respecto de Panamá y Costa Rica, en términos de gasto público por habitante. Como hemos dicho, la explicación reside en las desigualdades en el PIB y en las diferencias de tamaño relativo del sector público.

A esta altura del análisis es importante conocer las causas de las diferencias de gasto público como proporción del PIB entre los países de la subregión. Estas causas se encuentran en los mecanismos de captación de ingresos que utiliza el sector público de cada país. Si se examinan las fuentes de ingreso público en relación con el PIB (cuadro 3), se ven diferencias entre estos países en su capacidad de captar ingresos tributarios. En Costa Rica se aprecia un mayor ingreso tributario como proporción del PIB. No se dispuso de información sobre Panamá, pero se puede asumir que su situación tributaria es similar a la costarricense. Las demás economías muestran menor captación de ingresos tributarios, aunque las cifras de Nicaragua y Honduras son más altas, lo que explica en parte las diferencias de gasto mencionadas antes. Sin embargo, es interesante observar que, con independencia de las desigualdades observadas, en todos los países de la subregión la estructura tributaria descansa en los impuestos indirectos, lo que sugiere una deficiencia generalizada de sus sistemas tributarios.

En Costa Rica se comprueba además la existencia de otros ingresos que fortalecen el financiamiento del gasto. (Se puede suponer que algo parecido sucede en Panamá). Esto indica que la diversificación de las actividades públicas a través del sector descentralizado permite captar ingresos mediante el cobro de servicios prestados. La comparación es significativa con el caso de El Salvador, para cuyo sector público no financiero se dispone de información. En este caso, la diferencia con Costa Rica en el rubro "Otros ingresos" como proporción del PIB es notoria, lo que refleja disparidades relativas de desarrollo estatal. Nicaragua ha logrado una cantidad apreciable de transferencias del exterior para mantener cierta magnitud de gasto, lo que explica la existencia de una proporción importante en el rubro "Otros ingresos", y también explica otra parte de la diferencia del tamafio relativo de su sector público con el de El Salvador y Guatemala.

Finalmente, como se aprecia en el cuadro 3, las políticas de control fiscal han eliminado el endeudamiento como fuente de expansión del sector público en la mayor parte de las economías de la subregión. En el período al que se refiere el cuadro (1989-1993) se notan los efectos de las políticas fiscales aplicadas: en Costa Rica, El Salvador, Guatemala y Panamá los niveles de endeudamiento son bajos en relación con el PIB, y en Costa Rica y Nicaragua incluso hay superávit interno. Sin embargo, en Honduras y Nicaragua un apreciable endeudamiento externo ayuda a mantener un gasto más elevado y explica otra parte de las diferencias relativas de gasto con El Salvador y Guatemala. 

interno bruto, 1989-1993

(Porcentajes)

\begin{tabular}{|c|c|c|c|c|c|c|c|}
\hline & \multicolumn{3}{|c|}{ Ingresos tributarios } & \multirow{2}{*}{$\begin{array}{c}\text { Otros } \\
\text { ingresos }\end{array}$} & \multicolumn{3}{|c|}{ Endeudamiento } \\
\hline & Directos & Indirectos & Total & & Interno & Externo & Total \\
\hline Costa Rica ${ }^{a}$ & $9 .(X)$ & 12.83 & 21.82 & 30.43 & $-1.45^{b}$ & 0.67 & $-0.78^{b}$ \\
\hline E] Salvadora & 2.44 & 6.04 & 8.48 & 4.95 & 0.52 & 2,02 & 2.53 \\
\hline Guatemala ${ }^{c}$ & 1.93 & 5.66 & 7.59 & 1.86 & 0.99 & 0.31 & 1.31 \\
\hline Honduras ${ }^{c}$ & 3.98 & 10.73 & 14.71 & 2.26 & 1.36 & 4.87 & 6.22 \\
\hline Nicaragua ${ }^{c}$ & 3.23 & 13.81 & 17.04 & 7.56 & $-0.18^{b}$ & 4.50 & 4.32 \\
\hline Panamá & $+\cdots$ & $\cdots$ & $+\cdot$ & $\cdots$ & $\ldots$ & $\cdots$ & $\cdots$ \\
\hline
\end{tabular}

Fuente: CMCA, 1994. Elaboración propia.

a Sector públjco no fínanciero.

b El valor negativo indica superávit.

c Gobjerno central.

\section{La prioridad social y el nivel relativo del gasto social}

El último paso del análisis propuesto consiste en estudiar la prioridad otorgada al área social en la asignación de los recursos públicos. Para dar este último paso se examina el gasto social en relación con el gasto público total (cuadro 4). Las diferencias entre los países no son muy notorias, apreciándose valores que van del 34 al 39\%. Para Costa Rica y Panamá los valores podrían considerarse un tanto bajos, pero su dificultad de formular una política social clara en los años ochenta puede haber afectado el comportamiento de este indicador. En Nicaragua ha habido un esfuerzo por dar prioridad al área social a lo largo de una década y media, lo que se ha traducido en una mayor participación de los sectores sociales en la asignación de los recursos públicos. En los demás países, la prioridad asignada a lo social ha fluctuado sin una orientación definida, revelando la falta de una política social consistente.

Estas consideraciones sugieren que en las distintas economías de la subregión se podría dar mayor prioridad al área social siempre que se tuviera la capacidad de aplicar una política social apropiada a las necesidades de cada sociedad.

De no existir diferencias notorias en la prioridad otorgada a lo social, el gasto social por habitante es determinado principalmente por los otros aspectos analizados: la evolución del PIB y la situación fiscal.

Si se examina el gasto social por habitante en Centroamérica en 1992-1993 (cuadro 4), se observa lo que se indica a continuación. En Panamá y Costa Rica, debido al nivel del PIB por habitante y el tama- ño relativo del sector público, este gasto es de más de $\mathbf{4 0 0}$ dólares, cifra bastante elevada para las condiciones de la subregión. En las demás economías centroamericanas, en cambio, es inferior a 80 dólares, como efecto combinado de su PIB por habitante y del tamaño relativo del sector público en cada país, así como de diferencias menores en la prioridad otorgada al área social. El Salvador muestra un mejor nivel de gasto social por habitante gracias a su PIB por habitante, pero está limitado por el tamaño relativo de su sector público. Guatemala, que exhibe un PIB por habitante similar, no logra un nivel

\begin{tabular}{|c|c|c|}
\hline \multirow[t]{2}{*}{ CUADRO 4} & \multicolumn{2}{|c|}{$\begin{array}{l}\text { Centroamérica: Gasto social como proporción } \\
\text { del gasto público en } 1989-1993 \text { y gasto social } \\
\text { por habitante en } 1992-1993 \\
\text { (Porcentajes y dolares) }\end{array}$} \\
\hline & $\begin{array}{l}\text { Gasto } \\
\text { social } \\
\text { gasto } \\
\text { público } \\
\text { (porcentajes) }\end{array}$ & $\begin{array}{l}\text { Gasto social } \\
\text { por } \\
\text { habitante } \\
\text { (dólares) }\end{array}$ \\
\hline Costa Rica ${ }^{a}$ & 39.07 & $420^{b}$ \\
\hline E] Salvadora & 32.23 & $79^{\mathrm{c}}$ \\
\hline Guatemalad & 39.40 & $48^{c}$ \\
\hline Honduraşd & 34.01 & $56^{\mathrm{b}}$ \\
\hline Nicaraguad & 36.21 & $44^{c}$ \\
\hline Panamáa & $36.85^{\mathrm{e}}$ & $502^{c}$ \\
\hline
\end{tabular}

Fuente: CMCA, 1994; CRAS/UNICEF, 1994, Elaboración propia.

a Sector público no financiero.

b 1992 .

c 1993.

d Gobierno central.

e Estimaçión de 1989. 
parecido porque su sector público es aún más pequeño, y porque tiene dificultades para dar mayor prioridad a lo social de manera sostenida. Honduras y Nicaragua sufren los efectos de un nivel productivo muy bajo, a pesar de que su sector público es un

\section{IV}

\section{Conclusiones}

El debate acerca del mejoramiento de la financiación social en Centroamérica ha sido muy intenso en los últimos años, a la luz del cambio en la agenda política. Sin embargo, no siempre se ha estudiado con detenimiento las posibilidades reales de lograr tal objetivo. En páginas anteriores hemos mostrado los aspectos de orden global que condicionan el proceso de asignación de recursos al área social en Centroamérica, con miras a aportar elementos de juicio que permitan identificar las características básicas del proceso y definir un rumbo realista para los próximos años. De la información presentada se desprende que no es posible hacer generalizaciones, ni mucho menos pretender que se equipare a corto plazo el financiamiento social de los distintos países. Por lo tanto, el proceso de integración en el plano social debe partir de la aceptación de las diferencias y del diseño de planes de acción adecuados a esa realidad.

De conformidad con la metodología expuesta aquí, las posibilidades de mejorar la asignación de recursos a las acciones sociales en cada país dependen de tres factores básicos: i) el panorama futuro en materia de crecimiento del PIB y de crecimiento demográfico; ii) la ampliación del tamaño relativo del Estado, en un contexto de estabilidad fiscal (crecimiento proporcional del gasto público sobre la base de un financiamiento sano), y iii) una mayor prioridad a lo social en el proceso de asignación de recursos públicos.

Las perspectivas de crecimiento productivo en los próximos años no están suficientemente claras en la subregión. Hay un potencial significativo de expansión de la economía, basado en la promoción de las exportaciones; pero para materializarlo es preciso definir de manera apropiada, entre otros aspectos, la forma que tomará la apertura comercial (reconociendo la asimetría entre las partes), el proceso de reconversión de un aparato productivo bastante atrasado, la poco mayor, en términos relativos; pero no está claro que el nivel de su gasto público se pueda mantener ya que, como se dijo antes, una parte de él se ha logrado gracias a transferencias externas o endeudamiento externo. modernización de la infraestructura de apoyo a la producción (transporte, energía, comunicaciones, etc.) y la capacitación técnica de la fuerza laboral.

Las economías centroamericanas, en su mayoría, han iniciado en los años noventa una reactivación económica que se ha expresado en tasas positivas de crecimiento del PIB por habitante (cuadro 5). Sin embargo, esto no es prueba suficiente de que hayan terminado con éxito la transformación económica necesaria para garantizar una expansión sostenida. Se requiere también una respuesta en el plano demográfico. En varios de estos países, principalmente los más necesitados de elevar su PIB por habitante, el aumento de la población absorbe buena parte de la expansión productiva, lo que limita el incremento de ese PIB. Por lo tanto, si se desea ampliar la base material para el financiamiento social se debe lograr un crecimiento productivo importante y un incremento de la población que permita elevar sostenidamente el PIB por habitante.

Si se pretende aumentar el financiamiento social, la ampliación de la magnitud relativa del gasto público parece una condición ineludible para la mayor parte de los países de la subregión. Esta conclusión no es contraria a las políticas que hoy se aplican de manera generalizada en América Latina y el Caribe en torno a la modernización del Estado y la disciplina fiscal. De lo que se trata es de aceptar que en muchas de las economías centroamericanas la proporción de gasto público es muy baja, debido a un proceso histórico de rezago económico y social. En consecuencia, es necesario elevar esa proporción, pero sin perder la estabilidad fiscal, lo que se traduce en la necesidad de mejorar considerablemente los mecanismos de captación de los ingresos públicos.

Para hacerlo hay que ampliar el radio de acción de los sistemas tributarios, especialmente a través de mecanismos progresivos, y diversificar las fuentes de 
CUADROS

Centroamérica: Producto interno bruto por habitante, 1989 - 1993

(Tasas de crecimiento anuales)

\begin{tabular}{|c|c|c|c|c|c|}
\hline & 1989 & 1990 & 1991 & 1992 & 1993 \\
\hline \multicolumn{6}{|l|}{ Costa Rica } \\
\hline PlB & 5.67 & 3.56 & 2.26 & 7.29 & 5.49 \\
\hline Población & 2.78 & 2.67 & 2.57 & 2.51 & 2.44 \\
\hline $\begin{array}{l}\text { PIB por } \\
\text { habitante }\end{array}$ & 2.81 & 0.86 & -0.30 & 4.67 & 2.98 \\
\hline \multicolumn{6}{|l|}{ El Salvador } \\
\hline PIB & 1.06 & 3.40 & 3.53 & 5.14 & 4.98 \\
\hline Población & 1.91 & 1.99 & 2.07 & 2.22 & 2.24 \\
\hline $\begin{array}{l}\text { PIB por } \\
\text { habitante }\end{array}$ & -0.84 & 1.38 & 1.43 & 2.86 & 2.68 \\
\hline \multicolumn{6}{|l|}{ Guatemala } \\
\hline PIB & 3.94 & 3.10 & 3.66 & 4.78 & 4.00 \\
\hline Población & 2.93 & 2.93 & 2.94 & 2.93 & 2.94 \\
\hline $\begin{array}{l}\text { PIB por } \\
\text { habitante }\end{array}$ & 0.98 & 0.16 & 0.71 & 1.80 & 1.04 \\
\hline \multicolumn{6}{|l|}{ Honduras } \\
\hline PIB & 4.33 & 0.10 & 3.25 & 5.62 & 3.66 \\
\hline Población & 3.09 & 3.06 & 3.05 & 3.02 & 3.01 \\
\hline $\begin{array}{l}\text { PIB por } \\
\text { habitante }\end{array}$ & 1.20 & -2.88 & 0.19 & 2.52 & 0.63 \\
\hline \multicolumn{6}{|l|}{ Nicaragua } \\
\hline PIB & -1.70 & -0.13 & -0.16 & 0.36 & -0.88 \\
\hline Población & 2.68 & 3.06 & 3.59 & 3.91 & 4,04 \\
\hline $\begin{array}{l}\text { PIB por } \\
\text { habitante }\end{array}$ & -4.26 & -3.09 & -3.62 & -3.42 & -4.73 \\
\hline \multicolumn{6}{|l|}{ Panamá } \\
\hline PIB & -0.26 & 4.88 & 8.89 & 8.45 & 6.28 \\
\hline Población & 2.00 & 2.00 & 1.92 & 1.92 & 1.89 \\
\hline $\begin{array}{l}\text { PIB por } \\
\text { habitante }\end{array}$ & -2.21 & 2.82 & 6.84 & 6.40 & 4.31 \\
\hline
\end{tabular}

Fuente: CMCA, 1994; BID, 1994.

ingreso mediante una mayor descentralización de la acción estatal. La cooperación externa deberá desempeñar un papel muy importante como factor complementario de los esfuerzos internos de financiamiento y como apoyo para lograr resultados en el corto $y$ mediano plazo.

El otorgamiento de una mayor prioridad al área social también debe desempeñar un papel significativo en los próximos años, si se quiere ampliar el financiamiento social. El crecimiento medio de la economía y el aumento del nivel relativo del gasto público no garantizan por sí solos el incremento de la asignación de recursos al área social. Será necesaria una política explícita de apoyo prioritario a esa área para que se pueda captar los frutos de tales procesos en beneficio del financiamiento de los sectores sociales.

Es probable que sea necesario avanzar en todos estos campos — no sólo en algunos-- para que au- mente el financiamiento social en la subregión, dada la magnitud del rezago en este ámbito. Pero esto mismo revela que la ampliación de los recursos destinados al área social será un proceso largo, ya que los factores mencionados sólo rendirán sus frutos luego de un período de maduración. En consecuencia, es indispensable una voluntad nacional que permita la toma de las decisiones correspondientes y la continuidad en el tiempo de las políticas que se adopten.

Por otra parte, en las economías de la subregión que exhiben un mayor financiamiento social cobra especial importancia la evaluación de la eficiencia y eficacia del gasto público. En estos países, donde el gasto social por habitante ha logrado niveles mayores, debe analizarse con cuidado si es posible obtener mejores resultados con los recursos existentes. Es probable que el crecimiento del gasto haya ido acompanado de disminuciones de su productividad, por lo que para mejorar la asignación a lo social no sólo hay 
que ampliar los recursos, sino también elevar su rendimiento. Para ello deben plantearse medidas como la redistribución de recursos dentro de las instituciones, entre instituciones y entre regiones geográficas, a fin de obtener el máximo provecho de los recursos humanos y materiales. Esto es aplicable también a las demás economías centroamericanas, pero con menor intensidad, ya que en ellas el problema se relaciona más bien con insuficiencias en el nivel absoluto del financiamiento.

\section{Bibliografia}

BID (Banco Interamericano de Desartollo) (1994): Progreso económico y social en América Latina. Informe 1994. Washington, D.C.

CMCA (Consejo Monetario Centroamericano, Secretaría Ejecutiva) (1994): Boletín Estadístico 1993, San José, Costa Rica.

CRAS/UNICEF (Comisión Regional de Asuntos Sociales / Fondo de las Naciones Unidas para la Infancia) (1994): Financiamiento del área social en Centroamérica. Informe 1994, San José, Costa Rica.
Leipziger, Danny y Vined Thomas (1994): Las bases del exito de Asia oriental, Finanzas y Desarrollo, vol. 31, $\mathrm{N}^{\circ} 1$, Washington, D.C., Fondo Monetario Internacional/Banco Mundial, marzo.

Page, J. (1994): El milagro de Asia oriental: creación de una base para el éxito, Finanzas y desarrollo, vol. $31, \mathrm{~N}^{\circ} 1$, Washington, D.C., FMl/Banco Mundial, marzo.

PNUD (Programa de las Naciones Unidas para el Desarrollo) (1991): Desarrollo humano. Informe [99], Bogotá, Tercer Mundo Editores. 